\title{
Frontal sinus mucocoeles: new algorithm for surgical management*
}

\author{
A. Sama, J. Constable, L. McClelland \\ Department of Otolaryngology, Queen's Medical Centre, Nottingham, Nottinghamshire, NG7 2UH, United Kingdom
}

Rhinology 52: 267-275, 2014

DOI:10.4193/Rhino13.103

\begin{abstract}
Background: Frontal sinus mucocoeles require a structured approach to their surgical management. We share our experience of a novel method of positional classification for frontal mucocoele and corresponding surgical algorithm.
\end{abstract}

Methods: A retrospective case-note review examined all frontal sinus surgery for mucocoele, spanning three years (2008-2010). Patients had pre-operative nasendoscopy, multi-planar CT and MRI when indicated. Several important variables (position, drainage dimensions, fronto-ethmoidal cells and degree of neo-osteogenesis) were noted. A systematic algorithm was used for surgical drainage based on these characteristics. The three year outcomes using this approach are presented.

Results: Thirty-six patients were identified with a total of 43 frontal mucocoeles. Using our classification, 30 mucocoeles were medial; seven were intermediate; six were lateral. Thirty-four patients underwent a primary endoscopic procedure; six required a combined primary osteoplastic-flap (OPF) and endoscopic approach. Six patients required revision surgery for polypoidal change or neo-ostium stenosis. All patients were eventually rendered asymptomatic.

Conclusion: Implementation of our positional classification and surgical algorithm was successful with a revision rate of $19 \%$. Presence of frontal sinus wall dehiscence and extra-sinus mucocoele extension are invalid indicators for external approach. We feel our classification and treatment algorithm, with its associated indicators for surgical escalation (i.e. limited dimensions of frontal ostium, presence of Type III / IV front-ethmoidal cells etc), are applicable for future management of frontal mucocoeles.

Key words: frontal sinus, mucocoele, paranasal sinus diseases, natural orifice endoscopic surgery

\section{Introduction}

A mucocoele is a mucus-filled epithelial sac within a paranasal sinus, capable of expansion ${ }^{(1)}$. Mucocoeles are often idiopathic, but can be secondary to infection, nasal polyposis, trauma, previous surgery or neoplasms ${ }^{(2,3)}$. There is often a varied time delay between the causative event, mucocoele formation and symptoms manifesting ${ }^{(4)}$. They can cause displacement of the orbital and intracranial contents via bony destruction of the containing sinus' walls. If they become acutely infected, they are termed "mucopyocoele".

Approximately $65-89 \%$ of mucocoeles are within the frontal sinus, $8-30 \%$ are ethmoidal and less than $5 \%$ are maxillary ${ }^{(4,5)}$. Sphenoidal mucocoeles remain the rarest sinus to be complicated with a mucocoele ${ }^{(3,5,6)}$. Mucocoeles present equally in both genders and are most common in the $40-60$ year-old age group ${ }^{(6)}$. Historically, the surgical approach to mucocoeles has been an external approach. However, the modern day evidence base advocates endonasal surgery as the mainstay of today's management of mucocoeles ${ }^{\text {(7-12) }}$.

The terminology for endoscopic frontal sinus drainage surgery can be confusing due to multiple synonyms. Draf's original description states that a Type I drainage is established by 
ethmoidectomy including cell septa removal in the region of the frontal recess. The inferior part of the ethmoidal infundibulum and its mucosa is not touched. Extended drainage is achieved by resecting the frontal sinus floor between the lamina papyracea and middle turbinate (Type Ila), or to the nasal septum, anterior to the olfactory fossa's ventral margin (Type Ilb) ${ }^{(9,13)}$. Finally, a "Draf III" procedure opens the frontal sinus floor from the ipsilateral to contralateral lamina papyracea, whilst also removing the upper nasal septum and frontal inter-sinus septum ${ }^{(9,13)}$.

Only one frontal sinus mucocoele classification system is offered in the literature ${ }^{(7)}$.

This system is a radiological classification and offers no obvious correlate to the individual surgical procedure employed for a frontal sinus mucocoele. It is therefore our aim through consideration of a case series of our own, to discuss the important characteristics of a frontal mucocoele when deciding its surgical management, and to ultimately provide a surgical algorithm based on this.

\section{Materials and methods}

We present a new method for classification of frontal mucocoeles based on the mucocoele's position. Position was classified radiologically according to the mucocoele's most medial location on a sagittal plane. Mucocoeles presenting medial to the lamina papyracea's sagittal plane were classified as "medial", those presenting in the orbital rim's medial third as "intermediate" and all presenting lateral to this point as "lateral" (Figure 1).

Using this positional classification, each mucocoele's surgical management was then planned using our proposed surgical algorithm (Table 2). As no algorithm can take into account all of a mucocoele's pre-operative characteristics, the variables of greatest importance are included based on the senior author's experience with the literature duly considered.

These factors are namely the mucocoele's position, Anteroposterior (AP) and Latero-medial (LM) dimensions at the frontal ostia, presence of Type III/IV fronto-ethmoidal cells, degree of neo-osteogenesis, presence of contralateral frontal sinus disease and presence of other concurrent pathology.

The literature suggests the frontal drainage pathway dimensions at the level of the frontal beak ("Frontal ostium") to be a limiting factor when accessing frontal sinus pathology (14-16). The maximum AP dimension of the post-surgical neo-ostium is limited by the distance between the anterior projection of the cribriform plate and the frontal sinus' anterior plate in the axial plane (Figure 2a). Similarly, the LM dimensions can be limited by approximation of the lamina, or more often, collapse of lateral soft tissue secondary to loss of bony structural support from previous surgery or pathology (Figure 2b). From this, if the frontal ostium's maximum AP / LM dimensions were $<1 \mathrm{~cm}$, this was considered significant and a reason for surgical escalation

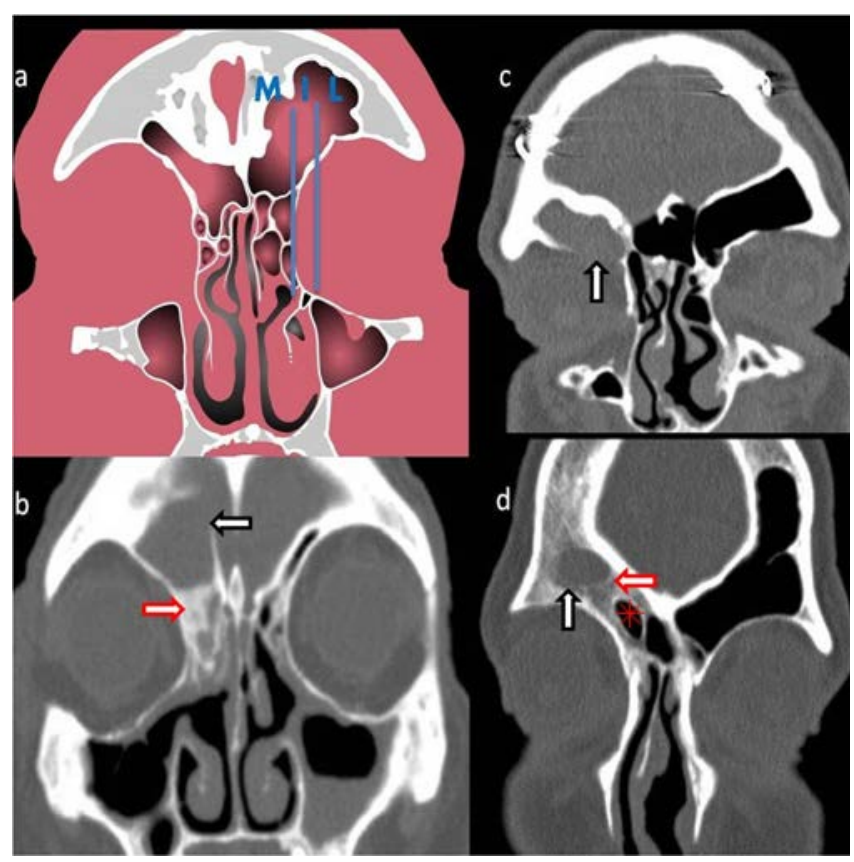

Figure 1. New classification for position of mucocoele with three radiological examples :- $M=$ medial, $I=$ intermediate, $L=$ lateral (Black arrow $=$ mucocoele, red arrow = neo-osteogenesis, red asterix = Type III Fronto-ethmoidal cell).

a. New classification for mucocoeles

b. Example of medial mucocoele with intra-cranial dehiscence

c. Intermediate mucocoele in patient with previous craniotomy and exposed cranial contents

d. Lateral mucocoele with evidence of notable neo-osteogenesis of drainage pathway and type III Fronto-ethmoidal cell.

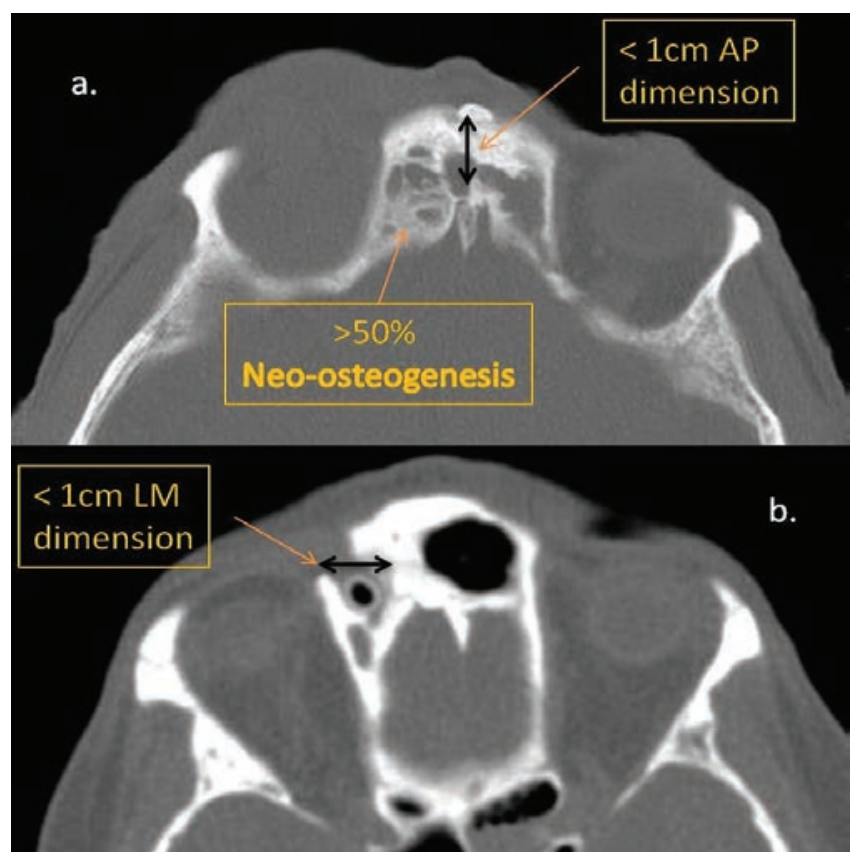

Figure 2. Examples of limited antero-posterior and latero-medial dimension of the frontal drainage pathway. 
Table 1. Mucocoele Classification ${ }^{(7)}$

\begin{tabular}{cl} 
Classification & Definiton \\
\hline 1 & Limited to frontal sinus ( \pm orbital extension) \\
\hline 2 & Fronto-ethmoidal ( \pm orbital extension) \\
\hline $3 a$ & $\begin{array}{l}\text { Erosion of the posterior sinus wall; minimal or no } \\
\text { intracranial extension }\end{array}$ \\
\hline $3 b$ & $\begin{array}{l}\text { Erosion of the posterior sinus wall; major intracra- } \\
\text { nial extension }\end{array}$ \\
& $\begin{array}{l}\text { Erosion of the anterior wall } \\
4\end{array}$ \\
\hline $5 a$ & $\begin{array}{l}\text { Erosion of the anterior and posterior wall; minimal } \\
\text { or no intracranial extension }\end{array}$ \\
\hline $5 b$ & $\begin{array}{l}\text { Erosion of the anterior and posterior wall; major } \\
\text { intracranial extension }\end{array}$
\end{tabular}

Table 2. Proposed endoscopic surgical algorithm for frontal sinus mucocoeles based on novel positional classification (Draf procedures).

\begin{tabular}{|c|c|c|c|}
\hline Complicating variable & Medial & Intermediate & Lateral \\
\hline No complicating factors & I/ lla & $\mathrm{Ila} / \mathrm{Ilb}$ & III \\
\hline \multicolumn{4}{|l|}{ AP/LM dimension, $<1 \mathrm{~cm}$} \\
\hline & $\mathrm{IIb}$ & III & III / OPF \\
\hline \multicolumn{4}{|l|}{ Type III / IV FE cell } \\
\hline$>50 \%$ neo-osteogenesis & III & III / OPF & OPF \\
\hline \multicolumn{4}{|c|}{ Key: AP / LM = Antero-Posterior / Latero-Medial: FE = Fronto-ethmoidal: } \\
\hline \multicolumn{4}{|c|}{ OPF = osteoplastic flap } \\
\hline \multicolumn{4}{|c|}{ Special Considerations:- (Escalate one step up the above table) } \\
\hline \multicolumn{4}{|l|}{ a. Supraorbital Mucocoele } \\
\hline \multirow{2}{*}{\multicolumn{4}{|c|}{$\begin{array}{l}\text { b. Secondary to other pathology- Osteoma / Inverted Papilloma / Pott's } \\
\text { puffy tumour / Samter's triad / Malignancy }\end{array}$}} \\
\hline & & & \\
\hline \multicolumn{4}{|c|}{ c. Significant intracranial extension / involvement } \\
\hline \multicolumn{4}{|c|}{ d. Bilateral mucocoele / pathologies } \\
\hline \multicolumn{4}{|c|}{ e. Revision / Revision surgery } \\
\hline
\end{tabular}

(Figure 2) ${ }^{(14-16)}$.

Anatomical variants such as Type III / IV fronto-ethmoidal cells, intersinus septal cells, supraorbital cells and bulla frontalis cells can compromise the frontal sinus drainage pathway (Figure 3). Therefore these cells require removal, which in turn requires a wider, greater access. Similarly, the presence of contralateral disease (infection, polyposis, mucocoele or tumours) needs both

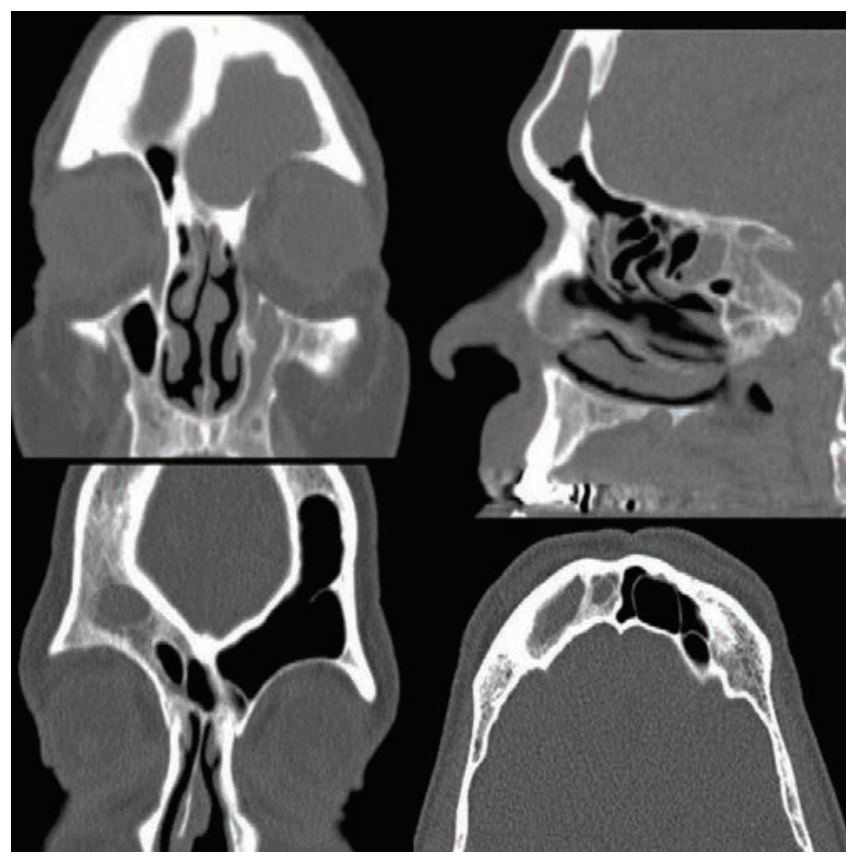

Figure 3. Examples of frontal mucocoele with associated Type III / IV Fronto-ethmoidal cells

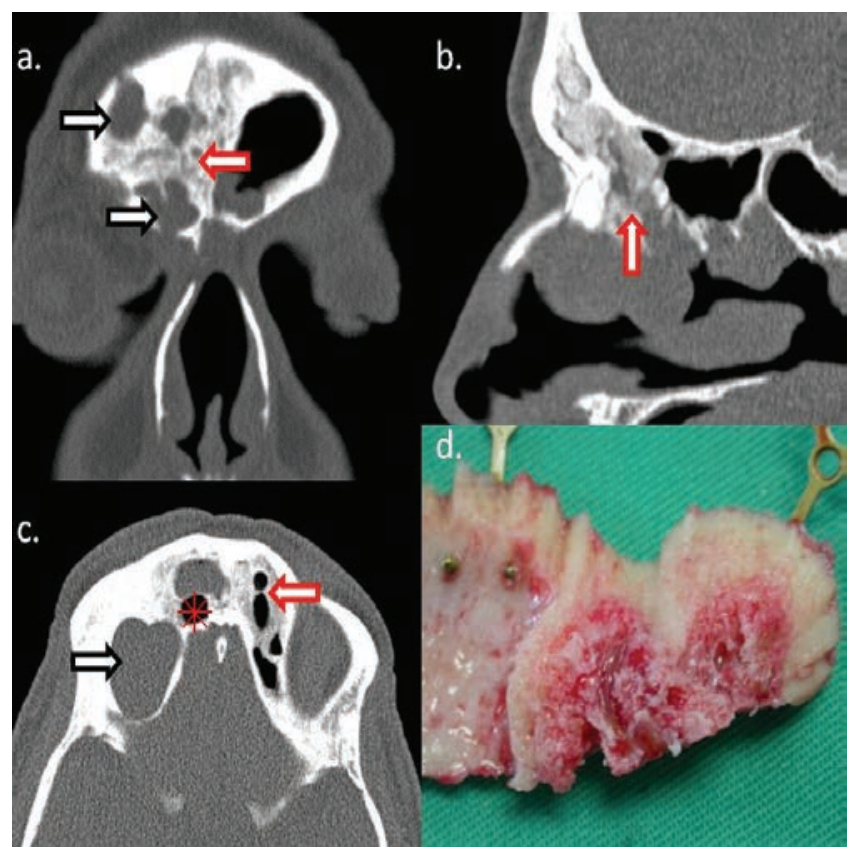

Figure 4. Examples of neo-osteogenesis.

(white arrow $=$ mucocoele, red arrow $=$ neo-osteogenesis, red asterix $=$ Type III Fronto-ethmoidal cell)

a. Coronal scan demonstrating multiple mucocoeles

b. Sagittal scan with extensive neo-osteogenesis of frontal drainage pathway.

c. Axial scan of lateral mucocoele, type III fronto-ethmoidal cell and contralateral neo-osteogenesis.

d. Operative images showing macroscopic appearance of extensive unilateral, frontal neo-osteogenesis. 
sides addressing, often with the midline Draf III procedure. Neo-osteogenesis due to chronic inflammation and osteitis can occur within the frontal sinus, "frontal ostia", or frontal recess (Figure 4). This significantly reduces the drainage pathway dimensions and importantly signifies a notable inflammatory load and therefore high re-stenosis risk. With no previous neo-osteogenesis classification described, we propose that if $>50 \%$ of the frontal sinus, "frontal ostium" or frontal recess was encroached due to neo-osteogenesis, this would be considered significant. Rarely, mucocoeles can develop secondary to neoplasia (e.g. inverted papillomas, osteomas or malignancy). When two separate pathologies are evident, the surgery should ideally address both. In our experience this required surgical escalation to a Draf III or even a concurrent osteoplastic flap (OPF) approach.

A three-year (2008-2010) retrospective case note review of all frontal sinus surgery for mucocoele under the senior author's care was carried out in order to appreciate the validity of our proposed classification and surgical algorithm. There were no exclusion criteria. Patients had pre-operative nasendoscopy and imaging with multi-planar sinus CT (sagittal, coronal and axial) and MRI if indicated (for intra-orbital or intra-cranial involvement). All the case notes were reviewed for symptoms, mucocoele pre-operative characterisation, primary procedure and operative outcome.

\section{Results}

Our review identified 36 patients ( 27 males, 9 female) with 43 frontal mucocoeles. Their mean age was 56 years (range 27 - 86 years) and 34 of these patients were operated on by a senior surgeon for frontal mucocoele.

\section{Presenting Symptoms}

Table 3 describes the range and frequency of presenting symptoms. Pain (78\%) and orbital symptoms (75\%) were the most frequent. Twenty-three patients (64\%) were noted to have proptosis on clinical or radiological examination. One patient was entirely asymptomatic, an incidental expansile frontal mucocoele was found on an MRI scan.

\section{Patient histories}

Twenty-four patients (67\%) had a history of previous operations to the sinus and facial region (average $=2.75$ operations per patient), of which ten patients (28\%) had experienced previous orbito-cranio-facial trauma. Eleven patients (31\%) had been previously operated on by another clinician or institution for their mucocoele. One patient presented with recurrence five years after previous endoscopic surgery under our care.

Approximately one quarter of the patients presenting with frontal mucocoeles had concurrent inflammatory or neoplastic disease in other sinuses including the ethmoids, maxillary and sphenoid sinuses.
Table 3. Presenting symptoms.

\begin{tabular}{lc} 
Presenting symptom & Number \\
\hline Pain and Headaches & \\
Facial pain / pressure & 15 \\
Frontal headache & 12 \\
Orbital symptoms & \\
Proptosis & 23 \\
Diplopia & 13 \\
Periorbital swelling & 11 \\
Proptosis & 7 \\
Periorbital cellulitis & 5 \\
Nasal Symptoms & \\
Post nasal drip & 7 \\
Rhinorrhoea & 4 \\
Nasal obstruction & 3 \\
Nasal discharge & 1
\end{tabular}

\section{Classification}

Pre-operatively, multi-planar CT imaging was used to characterise all 43 mucocoeles in terms of the important variables accounted for in our surgical algorithm (Table 2). Of the 36 patient cohort (with 43 mucocoeles), five had bilateral mucocoeles and one patient had three separate frontal mucocoeles (previous craniotomy for meningioma). Of the 43 mucocoeles, 40 were "frontal" (i.e. entirely above the level of the frontal beak) whilst three were "fronto-ethmoidal"- extending into the ethmoidal complex.

Using our new classification, 30 of the 43 mucocoeles were "medial", seven were "intermediate", and six were "lateral" (Table 4). Thirty-nine mucocoeles (91\%) showed orbital involvement (inferior wall dehiscence) and 16 (37\%) had posterior table erosion, although only nine (21\%) of these showed significant intra-cranial extension (Figure 5). Fifteen mucocoeles (35\%) had anterior plate erosion with two draining externally through a fistula.

The mucocoeles were grouped using both the traditional morphological classification, and our proposed positional classification. In order to make a comparison between the two classification systems, the frequency of operations performed for each mucocoele group were recorded (Table 4).

\section{Procedures}

After imaging, surgical management was tailored according to the proposed surgical algorithm (Table 2). Of the original 36 patients (with 43 mucocoeles), two patients (one with two mucocoeles) were managed conservatively due to anaesthetic contraindications. Thirty-two (94\%) of the remaining 34 patients were managed entirely in-keeping with the proposed algorithm whilst two patients' procedures were de-escalated due to significant medical co-morbidities necessitating shorter operative time. 
Table 4. Frequency of primary management: traditional morphological classification versus proposed positional classification.

\begin{tabular}{|c|c|c|c|c|c|c|}
\hline $\begin{array}{l}\text { Mucocoele } \\
\text { classifica- } \\
\text { tion - } \\
\text { "traditional" }\end{array}$ & $\begin{array}{l}\text { Medical } \\
\text { manage- } \\
\text { ment }\end{array}$ & $\begin{array}{c}\text { Draf } \\
\text { Ila }\end{array}$ & $\begin{array}{c}\text { Draf } \\
\text { Ilb }\end{array}$ & $\begin{array}{c}\text { Draf } \\
\text { III }\end{array}$ & $\begin{array}{c}\text { OPF + } \\
\text { Draf } \\
\text { III }\end{array}$ & Total \\
\hline 1 & 0 & 1 & 2 & 10 & 1 & 14 \\
\hline 2 & 0 & 2 & 0 & 0 & 0 & 2 \\
\hline $3 a$ & 1 & 0 & 0 & 5 & 0 & 6 \\
\hline $3 b$ & 0 & 0 & 2 & 0 & 2 & 4 \\
\hline 4 & 0 & 0 & 2 & 4 & 1 & 7 \\
\hline $5 a$ & 2 & 2 & 0 & 2 & 0 & 5 \\
\hline $5 b$ & 0 & 0 & 2 & 2 & 1 & 5 \\
\hline $\begin{array}{l}\text { Mucocoele } \\
\text { classifica- } \\
\text { tion - } \\
\text { "proposed" }\end{array}$ & $\begin{array}{l}\text { Medical } \\
\text { manage- } \\
\text { ment }\end{array}$ & $\begin{array}{c}\text { Draf } \\
\text { Ila }\end{array}$ & $\begin{array}{l}\text { Draf } \\
\text { Illb }\end{array}$ & $\begin{array}{c}\text { Draf } \\
\text { III }\end{array}$ & $\begin{array}{c}\text { OPF + } \\
\text { Draf } \\
\text { III }\end{array}$ & Total \\
\hline Medial & 3 & 4 & 7 & 12 & 4 & 30 \\
\hline Intermediate & 0 & 0 & 1 & 6 & 0 & 7 \\
\hline Lateral & 0 & 0 & 0 & 5 & 1 & 6 \\
\hline Sub-total & 3 & 4 & 8 & 23 & 5 & 43 \\
\hline Total & & & & & & 43 \\
\hline
\end{tabular}

Key: OPF = osteoplastic flap

Of the 40 surgically managed mucocoeles, 27 were medial, and of these, 23 (85\%) were drained endoscopically and four required a combined approach in accordance with the proposed algorithm's indications for operative escalation. All seven intermediate mucocoeles were drained endoscopically. Concerning the six lateral mucocoeles, only one patient (17\%) required a combined approach (recurrent frontal osteoma, 15 previous operations and subcutaneous fistula).

Neither classification shows a demonstrable correlation between classification and procedure required, although the proposed classification does show the trend that a larger neo-ostium is necessary as the mucocoele lateralises (Table 4). Forty-one percent of the medial mucocoeles operated on were adequately drained with a unilateral endoscopic approach (Draf $\mathrm{Ila} / \mathrm{llb}$ ), whilst only $14 \%$ of the intermediate and none of the lateral mucocoeles could be managed with a unilateral procedure. However, $59 \%$ of the medial mucocoeles required a bilateral procedure (Draf III or OPF) confirming that no simple mucocoele classification system is likely to account for every operation-

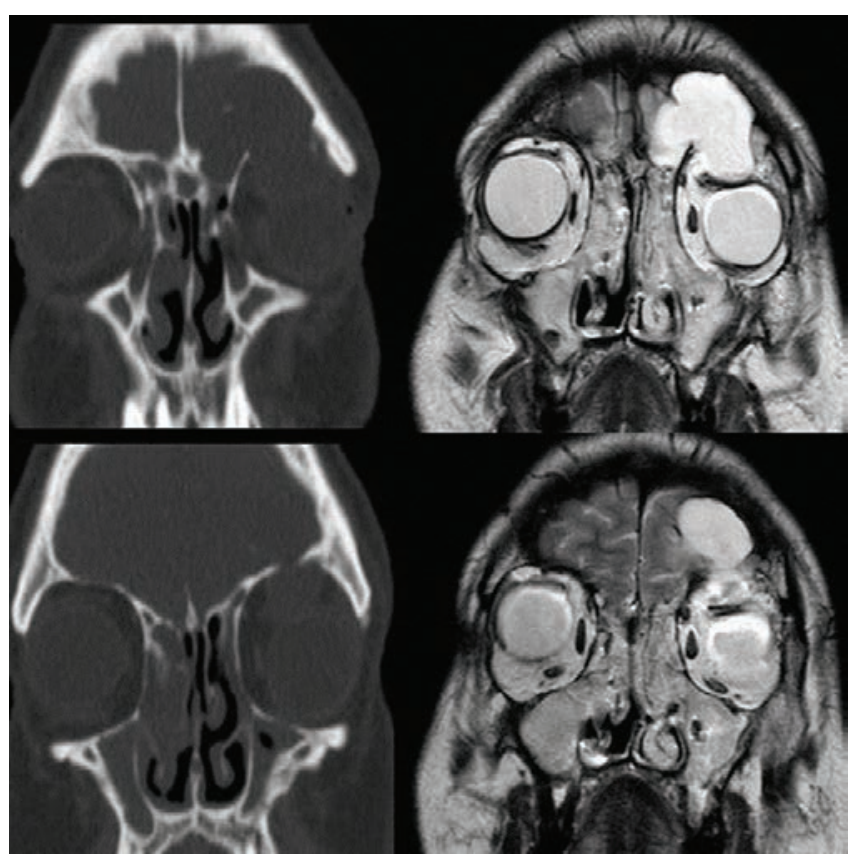

Figure 5. Sequential CT and MRI scans demonstrating a medial mucocoele with significant intracranial and orbital expansion.

determining variable.

The older, morphological classification is based on radiological evidence of erosion and extension, with the magnitude of the classification number (1 to $5 \mathrm{~b}$ ) intending to signify the mucocoele's complexity. However, $79 \%$ of the Class 1 mucocoeles needed a bilateral procedure, whilst $40 \%$ of the Class $5 \mathrm{~b}$ were managed unilaterally. This suggests that mucocoele erosion and extension does not affect management, but rather it is the mucocoele's position in relation to the drainage pathway that is important, and the other main co-existent factors as emphasised by our proposed surgical algorithm (Table 2).

\section{Post-operative outcomes and complications}

Post-operatively, the patients and their frontal sinus ostia were endoscopically followed up as outpatients for a minimum of two years (Range: 2 years, 1 month -3 years, 8 months). All 23 patients presenting with pre-operative proptosis improved post-surgery. None required repair of orbital dehiscence. Of the 13 patients who presented with pre-operative diplopia, 12 (92\%) settled post-surgery whilst one patient required an ophthalmic procedure for persistent diplopia from extra-ocular rectus muscle fibrosis.

Two of the 34 post-operative patients were lost to follow-up after multiple non-attendances. Table 5 summarises the outcomes of the remaining 32 patients. In the immediate post-operative period there were no surgical complications of infection, bleeding, orbital damage or cerebrospinal-fluid leak. 
Table 5. Primary outcome for 32 post-operative patients.

\begin{tabular}{|c|c|c|c|c|}
\hline \multirow{3}{*}{\multicolumn{2}{|c|}{$\begin{array}{c}\text { Mucocoele } \\
\text { characteristics }\end{array}$}} & \multicolumn{3}{|c|}{$\begin{array}{l}\text { Outcome of primary } \\
\text { neo-ostium (\# of pts) }\end{array}$} \\
\hline & & \multirow[t]{2}{*}{ Patent } & \multicolumn{2}{|c|}{ Compromised } \\
\hline & & & $\begin{array}{l}\text { Polypoid } \\
\text { obstruc- } \\
\text { tion }\end{array}$ & $\begin{array}{l}\text { Ostium } \\
\text { stenosis }\end{array}$ \\
\hline \multirow[t]{3}{*}{ Location } & Medial & 16 & 2 & 2 \\
\hline & Intermediate & 6 & 0 & 0 \\
\hline & Lateral & 4 & 1 & 1 \\
\hline \multirow{2}{*}{$\begin{array}{l}\text { LM / AP } \\
\text { dimension }\end{array}$} & $>1 \mathrm{~cm}$ & 20 & 2 & 2 \\
\hline & $<1 \mathrm{~cm}$ & 6 & 1 & 1 \\
\hline \multirow{2}{*}{$\begin{array}{l}\text { Pre-operative } \\
\text { neo- } \\
\text { osteogenesis }\end{array}$} & $<50 \%$ & 20 & 1 & 1 \\
\hline & $>50 \%$ & 6 & 2 & 2 \\
\hline \multirow{2}{*}{$\begin{array}{l}\text { Type III / IV } \\
\text { fronto- } \\
\text { ethmoidal cell }\end{array}$} & absent & 18 & 3 & 2 \\
\hline & present & 8 & 0 & 1 \\
\hline \multirow{4}{*}{$\begin{array}{l}\text { Associated } \\
\text { pathology }\end{array}$} & osteoma & 1 & 0 & 0 \\
\hline & PPT & 1 & 0 & 0 \\
\hline & AVM & 1 & 0 & 0 \\
\hline & IP & 0 & 0 & 1 \\
\hline \multirow{4}{*}{$\begin{array}{l}\text { Frontal } \\
\text { neo-ostium } \\
\text { type }\end{array}$} & Draf Ila & 4 & 0 & 0 \\
\hline & Draf IIb & 7 & 0 & 0 \\
\hline & Draf III & 13 & 2 & 1 \\
\hline & Draf III+OPF & 2 & 1 & 2 \\
\hline \multicolumn{2}{|l|}{ Total } & 26 & 3 & 3 \\
\hline
\end{tabular}

Key: PPT = Pott's puffy tumour: AVM = arterio-venous malformation: IP = inverted papilloma: OPF = osteoplastic flap

Of the 32 patients who were successfully followed-up, 26 (81\%) were cured of their mucocoele(s) and sinus disease subsequent to their first surgical intervention. Five patients developed polypoid change within the frontal neo-ostium, two of which responded fully to oral and topical steroids. The remaining three patients (9\%) were refractory to medical management with resultant neo-ostium obstruction. Another three patients (9\%) suffered non-polypoidal asymptomatic neo-ostium stenosis. Six patients (18\%) required revision surgery for re-stenosis or polypoidal obstruction of the neo-ostium. Three of these initial revisions were rendered asymptomatic, however the other three patients required further management.

The data in Table 5 suggests that the rate of stenosis was higher for "lateral" mucocoeles, those with AP / LM distance of $<1 \mathrm{~cm}$, those with $>50 \%$ neo-osteogenesis, those with Type III / IV fronto-ethmoidal cells present, and those having Draf III procedure or greater. This is explored further in the discussion.

\section{Discussion}

The operative repertoire for frontal mucocoele ranges from least to most invasive (i.e. endoscopic to open), with the chosen procedure selected to be minimally destructive whilst achieving adequate drainage and preventing recurrence. The endoscopic approach is favoured where possible with its relatively low morbidity, reduced inpatient stay and post-operative recovery duration, optimal cosmesis, and minimised risk of damage to the supra-trochlea or supra-orbital nerve bundle. Which mucocoele characteristics necessitate operative escalation, is not adequately described in the literature.

\section{Classification of frontal mucocoele position}

The only classification presented in the literature for mucocoeles is a radiological classification system ${ }^{(7)}$. Whilst the system does represent the progression of a radiologically expanding mucocoele, it has no clinical correlation with the surgical approach and drainage required, as demonstrated by our data (Table 4). Additionally, as substantiated by our series, there is increasing evidence that frontal / orbital wall dehiscence and intra-cranial expansion have little bearing on the surgical approach. The literature's nomenclature for frontal mucocoele position lacks clarity. Often, a "lateral" mucocoele is indistinctly defined by either the mucocoele's lateral extent, or the position of the dehiscence caused by the mucocoele. For example, Vaughan et al. in their series of 10 "lateral" mucocoeles, defined "lateral" as - "lesions involving or extending to the lateral aspect of the frontal sinus" (17). Scher et al. do not offer such a definition, but instead state "the cyst did not protrude into the frontal recess" ${ }^{(18)}$. They advocate a mini-OPF approach for "lateral" based mucocoeles" (18). Whilst these definitions qualify the series they present, they do not provide an accurate, reproducible method of classifying position. It is our belief that it is the mucocoele's most medial presentation rather than its lateral extent, that should define its position. We therefore present a new, clear system for defining position, using a fixed and reliable marker (sagittal plane of lamina papyracea) in order to offer three possible classifications (medial, intermediate and lateral - described in Methods).

\section{Revision rates}

The efficacy of the proposed surgical algorithm can be judged in the first instance by considering our surgical revision rate. However, the literature lacks data to assess the true revision surgery rate for frontal mucocoeles. Some authors have considered frontal mucocoeles as part of frontal surgery in general, others have looked at revision surgery in all the paranasal sinuses whilst some have had a relatively short follow-up period. Draf, in his series of 255 patients with paranasal sinus mucocoeles quoted a revision rate of $1.6 \%$. This included 51 patients with a frontal mucocoele and 23 patients with a front-ethmoidal 
mucocoele, all treated endoscopically ${ }^{(19)}$; relatively few surgeons have equalled his skill. Georgalas et al. considered the outcomes of 122 patients who underwent a Draf III procedure, of which 18 patients $(15 \%)$ had a frontal mucocoele, with an overall revision rate of $31 \%$ for all pathologies and $5.6 \%$ for mucocoeles ${ }^{(20)}$. Sethi et al., in his series of 44 endoscopically treated fronto-ethmoidal mucocoeles, reported a revision rate of $5 \%$ with a further $7 \%$ of patients having stenosis which did not undergo revision ${ }^{(21)}$. Suárez reported 72 patients with paranasal mucocoeles (frontal, fronto-ethmoidal and maxillary), 48 of which were treated endoscopically with a revision rate of $4 \%{ }^{(22)}$. Wormald et al., in a similarly mixed series of 41 mucocoeles (28 patients), had a Draf III frontal sinus stenosis rate of $14 \%{ }^{(23)}$.

Our series' revision rate is 19\% (6 / 32 patients; 3 with asymptomatic stenosis and 3 with polypoidal neo-ostium obstruction) with none exhibiting mucocoele recurrence. The rate of neo-ostium stenosis was highest for individuals with "lateral" mucocoeles, AP / LM dimensions $<1 \mathrm{~cm},>50 \%$ neo-osteogenesis, presence of Type III / IV fronto-ethmoidal cells, and Draf III procedures. This confirms the validity of our surgical algorithm's indicators for operative escalation, as despite being given a larger neo-ostium size, patients with these pre-operative characteristics were still predisposed to the highest rates of stenosis.

\section{Management of posterior-table erosion and intra-cranial expansion}

The literature's recommendations for management of mucocoele intra-cranial extension are varied, with some advocating cranialisation ${ }^{(24,25)}$. This in part reflects their neurosurgical background. Opposing cranialisation, Har-El presented 108 patients with paranasal sinus mucocoeles, $60 \%$ of which with varying intra-cranial extension, however, all patients were managed endoscopically, with only one revision for mucocoele recurrence (26). Citardi et al. presented a case series of patients with posterior table dehiscence associated with chronic rhinosinusitis and mucocoele, all of which were adequately treated endoscopically ${ }^{(27)}$. In our three year series, we have 16 cases (44\%) of posterior wall dehiscence with nine (25\%) demonstrating significant intra-cranial extension (Figure 5). Of these nine, the majority (67\%) were managed endoscopically. Three required combined Draf III and OPF for other indications i.e. $>50 \%$ neo-osteogenesis and concurrent $<1 \mathrm{~cm}$ AP dimension of the frontal ostium. Overall, our experience is in-keeping with published ENT literature and we confirm that endoscopic marsupialisation without reconstruction is perfectly adequate for mucocoeles with posterior table or skull base dehiscence, with or without intra-cranial expansion.

\section{Management of anterior-table erosion}

Schlosser et al. presented 37 patients with frontal mucocoele, complicated by anterior wall erosion ${ }^{(28)}$. Ninety-two percent (34 / 37 patients) were managed endoscopically and only one patient required additional anterior wall re-contouring with a plate. Schlosser proposed an algorithm with an endoscopic approach being first line. In our series, we have 11 patients with anterior table dehiscence and two of these with a frontal sinus-cutaneous fistula. All cases were successfully managed endoscopically. As was the experience of Schlosser, reconstruction of the anterior table has not been necessary for any of our patients, with all reporting an acceptable cosmetic defect. When present, fistulas were successfully excised at the same time as the primary endoscopic procedure.

Our experience and the literature agree that it is not necessary it to repair areas of bony dehiscence. Any residual bony deformity often requires time to re-model ${ }^{(4,11,29)}$. The lining of the sinus mostly returns to normal appearance with mucociliary clearance re-established within weeks, however, bony re-modelling may take significantly longer ${ }^{(8,12)}$.

\section{The external approach}

A bi-coronal incision and OPF without obliteration is our preferred external approach for frontal mucocoele. Our proposed algorithm justifies it in the following circumstances:

- Poor access to the supra-orbital cell.

- Multiple (>3) co-existent complicating factors (i.e. narrow AP/LM dimension etc).

- In the presence of malignancy or notable second pathology (e.g. Grade III frontal osteoma).

\section{Conclusion}

Frontal sinus mucocoeles are heterogeneous in origin. They are uncommon and most frequently present with orbital symptoms, which frequently resolve post-operatively. In a surgical context, the literature lacks a meaningful classification for frontal mucocoele, so we present a positional classification for frontal mucocoeles and a corresponding algorithm for their predominantly endoscopic surgical management. The aim should be to employ a minimally invasive procedure that adequately marsupialises the mucocoele and achieves a normal drainage pathway, with less concern for repairing bony wall dehiscence. Our results confirm that frontal mucocoele surgery is not a "one size fits all" entity. Careful attention must be paid to numerous factors related to the mucocoele's position, associated pathology and the drainage pathway's anatomical constraints. There are several important variables that determine the surgical options for drainage. The proximity of the mucocoele's most medial presentation to both the midline and frontal drainage pathway, the maximal AP / LM dimensions at the narrowest portion of the frontal drainage pathway, the presence and significance of fronto-ethmoidal (Type III / IV) cells, neo-osteogenesis, contralateral sinus disease, or neoplastic disease if applicable. Our own series justifies these comments, as the vast majority of our patients were treated endoscopically even when the mucocoele 
extended laterally ${ }^{(29)}$. Conversely, the majority of the previously considered "simpler" medial mucocoeles required a more extensive procedure due to co-existence of important complicating factors. No classification system can accommodate such a wide range of variables. Instead, we propose a new positional classification system and corresponding surgical algorithm that incorporates all the aforementioned factors (Table 1).

Cases of mucocoele recurrence, or those secondary to orbitocranio-facial trauma or surgery, are often suitably treated with a Draf III or combined OPF approach. Dehiscence or defects of the anterior table, posterior table or skull base are not uncommon. These should primarily be managed endoscopically and their presence is not a valid indication for open approaches or obliteration. The latter is reserved for revision due to re-stenosis or for other unrelated indications for open approach surgery. Although endoscopic sinus surgery has revolutionised mucocoele management there is still a limited role for open procedures such as the combined Draf III and OPF without obliteration. In our experience this should be reserved for patients with co-existent neoplastic pathology, multiple (>3) complicating factors or to address an isolated lateral supraorbital cell with poor endoscopic access.

\section{Authorship contribution}

AS - Senior author. Prof. Sama (ENT consultant) created the mucocoele position classification and management algorithm presented in this paper. Prof. Sama made significant contributions to descriptive and analytical content of the paper within Methods, Discussion and Conclusions.

JC - Co-author. Dr. Constable (House Officer) collected, interpreted and presented the data in this paper. Dr. Constable made significant contributions to the methods and results sections. Dr. Constable also made contributions to the Discussion section and prepared the figures.

LMC - Co-author. Miss. McClelland (ENT consultant) completed the literature review and as such made significant contributions to the Introduction and Discussion sections.

\section{Conflict of interest}

We, as authors, have no conflicts of interest.

\section{References}

1. Lund V, Milroy C. Fronto-ethmoidal mucocoeles: a histopathological analysis. J Laryngol Otol. 1991; 105: 921-923.

2. Lund V. Anatomical considerations in the aetiology of fronto-ethmoidal mucocoeles. Rhinology. 1987; 25: 83-88.

3. Ng Y, Sethi D. Isolated sphenoid sinus dis ease: Differential diagnosis and management. Curr Opin Otolaryngol Head Neck Surg. 2011; 19: 16-20.

4. Lund V. Mucocoeles. In: Gleeson ed. Volume 2 of Scott-Brown's Otorhinolaryngology, Head and Neck Surgery. London: Hodder Arnold, 2008; 1531-1538

5. Lloyd G, Lloyd V, Lund L, Savy D, Howard D. Optimum imaging for mucocoeles. J Laryngol Otol. 2000; 114: 233-236.

6. Arrue $P$, Thorn Kany M, Serrano $E$. Mucocoeles of the paranasal sinuses: Uncommon location. J Laryngol Otol. 1998; 112: 840-844

7. Har-El G. Transnasal endoscopic management of frontal mucocoeles. Otolaryngo Clin North Am. 2001; 34: 243-251.

8. Philpott C, McKiernan D, Javer A. Selecting the best approach to the frontal sinus. Indian J Otolaryngol Head Neck Surg. 2011; 63: 79-84.

9. Draf W. The Frontal Sinus. In: Gleeson, ed. Volume 2 of Scott-Brown's Otorhinolaryngology, Head and Neck Surgery. London: Hodder Arnold, 2008, 1500-1530.

10. Jones NS. Management of the Frontal
Sinuses. In: Flint PW, Haughey $\mathrm{BH}$ Lund VJ, eds. Volume 1 of Cummings Otolaryngology - Head and Neck Surgery. Philadelphia: Elsevier, 2010; 775-784.

11. Beasley N, Jones NS. Paranasal sinus mucocoeles: modern management. Am J Rhinol. 1995; 9: 251-256.

12. Palmer J, Kennedy D. Concepts of endoscopic sinus surgery. In: Flint PW, eds Volume 1 of Cummings Otolaryngology - Head and Neck Surgery. Philadelphia: Elsevier, 2010; 759 - 774.

13. Weber R, Draf W, Kratsch B, Hosemann W, Schaefer. Modern concepts of Frontal Sinus Surgery. Laryngoscope. 2001; 111: 137-146.

14. Gross C. Surgical Treatments for symptomatic Chronic Frontal Sinusitis. Arch Otolaryngol H \& N. 2002; 126: 101-102.

15. Draf W. Endonasal sinus drainage Type I-III. In: Kountakis S, Senior B, Draf W, eds. The Frontal Sinus. Berlin: Springer-Verlag, 2005; 231

16. Georgalas C, Fokkens W. Approaches to the frontal sinus. In: Georgalas C, Fokkens W, Wytske J, eds. Rhinology and Skull Base Surgery: From the Lab to the Operating Room: An Evidence-Based Approach. New York: Thieme Medical Publishers, 2013; 376409

17. Chiu A, Vaughan W. Management of lateral frontal sinus lesions and supraorbital cell mucoceles. Am J Rhinol Allergy. 2004; 18 : 83-86.

18. Yanagisawa E, Scher D. Laterally positioned mucocoele of the frontal sinus. Ear Nose Throat J. 2002; 81: 202-204.
19. Bockmuhl U, Kratzsch B, Benda K, Draf W. Surgery for paranasal sinus mucocoeles: Efficacy of endonasal micro-endoscopic management and long term results of 185 patients. Rhinology. 2006; 44: 62-67.

20. Georgalas C, Hansen F, Videler W, Fokkens W. Long term results of Draf Type III (modified endoscopic Lothrop) frontal sinus drainage procedure in 122 patients: a single centre experience. Rhinology. 2011; 49: 195-201.

21. Dhepnorrarat $R$, Subramaniam S, Sethi D. Endoscopic surgery for fronto-ethmoidal mucoceles: a 15-year experience. Otolaryngol Head Neck Surg. 2012; 147: 345-350.

22. Obeso S, Llorente J, Pablo Rodrigo J, Sánchez R, Mancebo G, Suárez C. Paranasal sinus mucoceles: our experience in 72 patients. Acta Otorrinolaringol Esp. 2009; 60: 332-339.

23. Khong J, Malhotra R, Selva D, Wormald R. Efficacy of endoscopic sinus surgery for paranasal sinus mucocele including modified endoscopic lothrope's procedure for frontal mucocele. J Laryngol Otol. 2004; 118: 352-356.

24. Delfini R, Missori P, Lannetti G, Ciappetta P, Cantore G. Mucoceles of the paranasal sinuses with intracranial and intraorbital extension: report of 28 cases. Neurosurgery. 1993; 32: 901-906.

25. Maliszewski M, Ladziński P, Kaspera W Majchrzak K. Mucocoele and mucopyocoele of the frontal sinus penetrating to the cranial cavity and orbit. Neurol Neurochir 
Pol .2011; 45: 342-350.

26. Har-El G. Endoscopic management of 108 sinus mucoceles. Laryngoscope 2001; 111: 2131-2134.

27. Hurley D, Javer A, Kuhn F, Citardi M. The endoscopic management of chronic fronta sinusitis associated with frontal sinus posterior table erosion. Am J Rhinol. 2000; 14: 113-120.
28. Woodworth B, Harvey R, Neal J, Palmer J, Schlosser R. Endoscopic management of frontal mucoceles with anterior table erosion. Rhinology. 2008; 46: 231-237.

29. McClelland L, Rokade A, Sama A. Frontal Sinus Mucocoeles. Journal of ENT Masterclass. 2012; 4: 56-60.
Prof Anshul Sama

Department of Otorhinolaryngolgy Nottingham University Hospital NHS

Trust

Derby Road

Nottingham

NG7 2UH, United Kingdom

E-mail: anshul.sama@nottingham. ac.uk 